\title{
Tissue injury and repair in the female human reproductive tract
}

\author{
Lois A. Salamonsen \\ Prince Henry's Institute of Medical Research, PO Box 5152, Clayton, Victoria 3168, Australia
}

The female reproductive tract is unique in its capacity to remodel constantly throughout adult life. Some of the remodelling events that occur naturally in the uterus, specifically menstruation, parturition, endometrial regeneration and uterine involution, have features in common with events of tissue injury and repair in other tissues, where they may occur after injury or in association with various pathologies. This review draws comparisons between the normally occurring tissue 'injury' and repair in the reproductive tract and that occurring elsewhere.

The female reproductive tract is unique in its capacity to remodel constantly throughout adult reproductive life. The mechanisms of tissue breakdown, as seen at menstruation and parturition, have been subject to several recent reviews (Hulboy et al., 1997; Salamonsen and Lathbury, 2000; Curry and Osteen, 2001) and will be reviewed only briefly here. This article will also examine what is known of the mechanisms of tissue repair, which have not been well studied in the reproductive tract. Possible mechanisms will be indicated by inference from studies on repair in other situations and the need for further research will be highlighted.

\section{Tissue injury}

\section{Menstruation}

Menstruation is the loss of most of the functionalis layer of the endometrium of women, accompanied by bleeding, that occurs after withdrawal of steroid hormone support at the end of each menstrual cycle. Since the start of the 1990s, there has been a paradigm shift in the view of the mechanisms underlying menstruation, from a process that is initiated and maintained primarily by vascular events, to a process in which tissue destruction is a key feature.

During the late luteal phase of the cycle, widespread degeneration is observed in the basal lamina supporting the decidualized endometrial cells and the endothelium of blood vessels (Roberts et al., 1992). Scanning electron microscopy (Ludwig and Spornitz, 1991) has revealed that small lesions are apparent in the luminal epithelium on day 28 of the normal cycle. There is then very rapid but incomplete degeneration of the functionalis layer, exposing open blood vessels and glands. It can therefore be surmised that the primary event initiating menstruation is tissue destruction and that loss

Email: lois.salamonsen@med.monash.edu.au of blood vessel integrity is one consequence of this. Ancillary mechanisms have also evolved to ensure that the blood does not clot (Lockwood and Schatz, 1996) and that the bleeding stops by the time the tissue destruction has ceased (Salamonsen et al., 1999a). Vasoactive mediators such as prostaglandins, endothelins and nitric oxide have important roles in regulating blood loss (Salamonsen et al., 1999b) but these will not be discussed further in this review. Evidence now supports the concept that endometrial destruction is a consequence of the action of matrix degrading enzymes on extracellular matrix, both fibrillar matrix and basal lamina, with resultant loss of blood vessel integrity and shedding of most of the functionalis layer. These data are summarized below.

Menstruation is initiated by the fall in concentrations of oestrogen and progesterone resulting from the demise of the corpus luteum late in the menstrual cycle. The key evidence that menstruation is triggered by loss of steroid support of the tissue is that: (1) if progesterone concentrations are maintained artificially, menstruation does not occur; (2) administration of the progesterone receptor antagonist, mifepristone, during the proliferative and secretory phases of the cycle, results in uterine bleeding; (3) withdrawal of oestrogen and progesterone, as in the case of cyclical contraceptive use, results in uterine bleeding. However, oestrogen and progesterone concentrations fall rapidly with corpus luteum degeneration in all mammals with oestrous cycles, whereas only women and some old-world primates menstruate. Thus, there must be idiosyncrasies of the primate endometrium that regulate menstruation.

Hypoxia. The dogma regarding mechanisms of menstruation originated from the studies of Markee (1940), who examined the morphological changes in autologous endometrium transplanted to the anterior of the eye of the rhesus monkey, and postulated that the tissue destruction occurred by necrosis resulting from anoxia 
after constriction of the spiral arterioles. Furthermore, as the spiral arterioles are specific to the endometrium of primates that menstruate, it appeared reasonable that menstruation was dependent upon them. This hypothesis was questioned as early as 1961 by Hisaw and Hisaw (1961), who observed that menstruation still occurred in the endometrium of primates that had undergone atrophy and had no such coiled arteries. Furthermore, the occurrence of widespread anoxia has not been substantiated in the human endometrium: indeed the transcription factors HIF- $1 \alpha$ and HIF- $2 \alpha$, which represent the earliest known response to hypoxia, are barely detectable in the human endometrium and are not widespread during the peri-menstrual phase (Zhang and Salamonsen, 2002a), indicating that mechanisms other than hypoxia are responsible for initiating menstruation.

Inflammatory response. Inflammation is characterized by tissue oedema, recruitment of inflammatory cells to an area and associated release of pro-inflammatory cytokines. Finn (1986) postulated that menstruation could be regarded as an inflammatory process. There is a marked increase in the total number of leucocytes in the endometrium immediately before menstruation, when they comprise up to $40 \%$ of the total cells within the stromal compartment (Salamonsen and Woolley, 1999). In particular, cells of the myeloid lineage (neutrophils, eosinophils, macrophages or monocytes) are abundant. Mast cells become highly activated and release granular contents into the local microenvironment, and eosinophil products are also detected extracellularly. Cells of lymphoid origin, particularly uterine natural killer cells, are also present in the tissue in substantial numbers, but they appear somewhat earlier during the secretory phase, indicating a primary role in implantation and establishment of pregnancy (King et al., 1998).

Current data indicates that the inflammatory response in the endometrium occurs in response to the withdrawal of progesterone. Endometrial and peripheral blood leucocytes do not express progesterone receptors (summarized in Salamonsen et al., 2002), indicating that the recruitment of leucocytes into the endometrium is mediated indirectly via resident cells expressing progesterone receptors. A number of chemoattractive molecules (chemokines) are synthesized by endometrial cells (for a review, see Salamonsen et al., 2002) and at least one of these (interleukin 8 (IL-8); Kelly et al., 1994) is negatively regulated by progesterone. It is likely that chemokines produced by resident cells attract leucocytes to the endometrium just before menstruation. When activated, leucocytes produce a plethora of regulatory molecules, including cytokines, chemokines and a range of enzymes that are important either directly in matrix degradation, or indirectly by activation of other proteases. The known leucocyte proteases are detailed in
Table 1. Such mechanisms are clearly of importance at menstruation.

Matrix degrading enzymes. Immediately before and during menstruation, there is induction of the expression, secretion and activation of matrix metalloproteinases (MMPs), proteases that together have the capacity to degrade all of the components of the extracellular matrix. Importantly, these enzymes are secreted in latent forms, and must be activated extracellularly: this can be achieved by a variety of enzymes, including other MMPs (particularly MMP-3, MMP-9 and MT1MMP) and by leucocyte proteases such as tryptase and elastase. If a number of latent enzymes are present within a microenvironment, activation of one enzyme, such as MMP-3, can lead to a cascade of subsequent activations. Although progesterone is overall inhibitory to the expression of many MMPs, local regulators of MMP transcription (predominantly cytokines) are derived from endometrial stromal, epithelial and vascular cells, as well as leucocytes within the tissue (for a review, see Curry and Osteen, 2001). Such local regulation can explain the very focal nature of the expression of most MMPs at menstruation. The proMMPs known to be upregulated in the human endometrium at about the time of menstruation are detailed in Table 2. Important support for a critical role for MMPs in menstruation is that MMP activity, both gelatinase and collagenase (as opposed to immunoreactive protein and mRNA), is significantly increased in the endometrium at menstruation compared with other stages of the cycle (Zhang and Salamonsen, $2002 \mathrm{~b}$ ), and that specific inhibitors of MMP can prevent the breakdown of endometrial explants in culture (Marbaix et al., 1996). Natural tissue inhibitors of matrix metalloproteinases (TIMPs), which bind active forms of most MMPs with a 1:1 stoichiometry, are also present in the human endometrium (Zhang and Salamonsen, 1997). For MMP action within any microenvironment, the active form of an MMP must be in excess of that of TIMPs, thus providing a very fine balance between a stable tissue and a tissue that is degrading. A hypothetical scheme for the events leading to the tissue destruction at menstruation is shown in Fig. 1.

\section{Parturition}

The events of parturition, the shedding of the placenta and the subsequent uterine involution, involve substantial tissue destruction and subsequent repair and remodelling. Most of the mediators known to be involved in placental shedding appear to be similar to those that are important at menstruation: matrix-degrading enzymes, cytokines and growth factors, and products of leucocytes.

Little is known about the molecular mechanisms of placental shedding. Clearly, placental separation 
Table 1. Leucocyte proteases of potential relevance to menstruation

\begin{tabular}{|c|c|c|}
\hline Leucocyte & Protease & Potential substrate \\
\hline \multirow[t]{4}{*}{ Mast cell } & Tryptase & Activates proMMP-3, uPA \\
\hline & Chymase & Activates proMMP-1, proMMP-3; inactivates bradykinin \\
\hline & Chymotrypsin & Broad spectrum \\
\hline & Plasminogen activator & Plasminogen \\
\hline \multirow[t]{6}{*}{ Neutrophil } & Elastase & Elastin, proteoglycans, collagens III, IV \\
\hline & MMP-8 & Collagen I, III, VII, VIII and X \\
\hline & MMP-9 & Collagen IV, V and VII, elastin, FN, LN \\
\hline & MT1-MMP & $\begin{array}{l}\text { Activates proMMP-2, proMMP-13, degrades FN, } \\
\text { tenascin, nidogen, perlecan, collagen I and III }\end{array}$ \\
\hline & Heparanase & Heparan sulphate proteoglycans \\
\hline & Cathepsin G & Elastin, proteoglycans, collagen III and IV \\
\hline \multirow[t]{4}{*}{ Eosinophil } & MMP-1 & Collagen I, III, VII, VIII and X \\
\hline & MMP-9 & As above \\
\hline & $\beta$ glucuronidase & Proteoglycans \\
\hline & Aryl sulphatase & Proteoglycans, GAG \\
\hline \multirow[t]{4}{*}{ Macrophage } & MMP-9 & As above \\
\hline & Metalloelastase & Elastase, collagen IV, LN, FN, VN, heparin, chondroitin sulphates \\
\hline & MT1-MMP & As above \\
\hline & Plasminogen activator & As above \\
\hline \multirow[t]{2}{*}{ T lymphocyte } & MMP-2 & Gelatin, collagens, decorin, LN \\
\hline & MMP-9 & As above \\
\hline Uterine NK cell & MT1-MMP & As above \\
\hline
\end{tabular}

MMP: matrix metalloproteinase; uPA: urokinase plasminogen activator; FN: fibronectin; LN: laminin; GAG: glycosaminoglycan: VN: vitronectin; NK: natural killer. (Reproduced with permission from Salamonsen and Lathbury, 2000.)

Table 2. proMMP (matrix metalloproteinase: protein or mRNA) present in premenstrual and menstrual endometrium

\begin{tabular}{lllr}
\hline MMP & \multicolumn{1}{c}{ Alternative name } & \multicolumn{1}{c}{ Cellular location (protein) } & $\begin{array}{r}\text { Active forms } \\
\text { demonstrated }\end{array}$ \\
\hline MMP-1 & Interstitial collagenase & Stroma, focal points & Yes \\
MMP-2 & Gelatinase A & Stroma, endothelium, some epithelium, selected leucocytes & Yes \\
MMP-3 & Stromelysin 1 & Stroma, focal points & N/A \\
MMP-7 & Matrilysin & Glandular epithelium & N/A \\
MMP-9 & Gelatinase B & Neutrophils, macrophages eosinophils & Yes \\
MMP-10 & Stromelysin 2 & N/A & N/A \\
MMP-11 & Stromelysin 3 & N/A & N/A \\
MMP-14 & Membrane-type 1 MMP & Epithelium, some areas of decidualized stroma, selected leucocytes & N/A \\
MMP-15 & Membrane-type 2 MMP & Glandular epithelium, vascular smooth muscle & N/A \\
\hline
\end{tabular}

Derived from Salamonsen and Woolley (1999); Zhang et al. (2000); Curry and Osteen (2001) and Zhang and Salamonsen (2002b).

results in part from the contractile strain exerted by the myometrium (Deyer et al., 2000). Incomplete separation usually results from ineffectual uterine contractions. However, before separation, the placental extracellular matrix is likely to be weakened by the actions of proteases, thus permitting its separation from the uterus. Enzymes such as MMP-2 and MMP-9 are well recognized as important for the rupture of the membranes (Xu et al.,
2002) but it is their upregulation within the decidua or chorion that is likely to influence shedding. MMP-9 gene and protein together with MMP-9 activity are increased in choriodecidua during and after spontaneous-onset labour at term (Tsatas et al., 1999), whereas a decrease in the concentration of TIMPs at the materno-fetal interface during active labour (Riley et al., 1999) would shift the balance between enzymes and inhibitors in favour of 


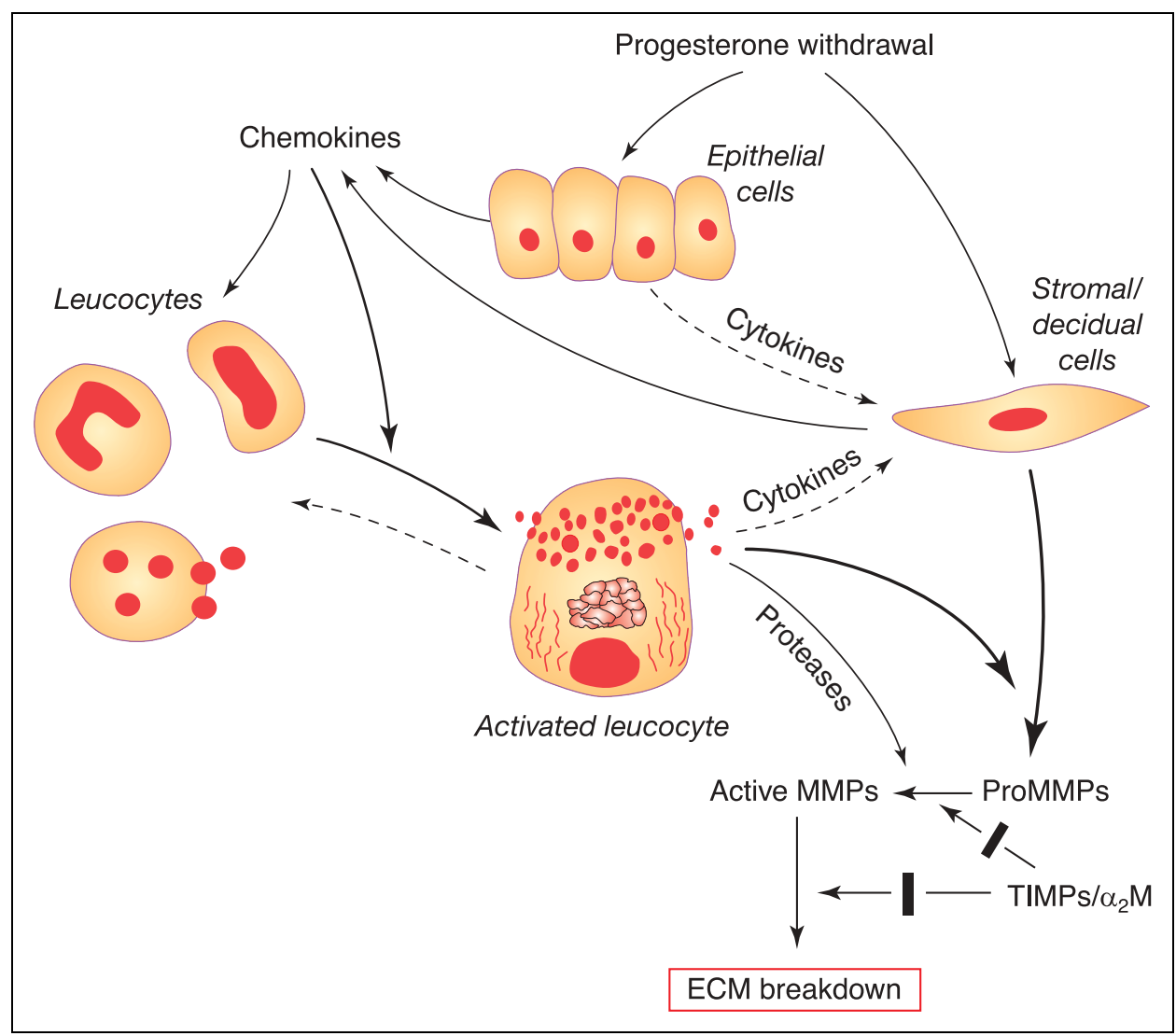

Fig. 1. Hypothetical scheme for the molecular and cellular events within the endometrium that govern the initiation of menstruation. These events follow withdrawal of progesterone in the secretory phase of the human menstrual cycle. This results in the production of chemokines, cytokines and other factors from endometrial epithelial, stromal and decidualized stromal cells. Leucocytes enter the tissue and become activated in response to chemokine signalling. Cytokines and other regulatory molecules from leucocytes, epithelial and other resident cells stimulate the production of matrix metalloproteinases (MMPs) from stromal cells and the production of MT1-MMP (which activates proMMP-2) in a variety of cells. Leucocytes also produce MMPs and other proteases that activate latent MMPs. The result is a cascade of MMP production and activation and an alteration in the balance between MMPs and tissue inhibitors of metalloproteinases (TIMPs) in favour of MMP action, resulting in degradation of tissue. $\alpha_{2} M: \alpha_{2}$ macroglobulin.

tissue degradation. Further studies examining regulation of protease production within this tissue and defining the cellular source and precise location of active forms of the enzymes are required.

\section{Tissue repair}

\section{Wound healing}

Wound healing is a dynamic interactive process involving soluble mediators, blood cells, extracellular matrix and parenchymal cells. It occurs in three phases: inflammation, tissue formation and tissue remodelling (for a review, see Singer and Clark, 1999). There are certain features of wound healing that are common to all tissues. However, there are important differences between tissues and a range of features from different models are likely to apply to endometrial repair. There are also aspects of wound healing in other adult tissues that appear to not apply to the endometrium, such as the development of granulation tissue that occurs during the healing of most cutaneous wounds and the formation of blood clots which provide important mediators for the initiation of repair.

Most wounds heal with scarring and this is not generally seen in endometrial repair in women, although in mice, postpartum 'nodules' have been reported (Brandon, 1990). The other situation in which scarless wound repair occurs is in fetal skin wounds. This changes with fetal development, the least scarring being at an early developmental age (Samuels and Tan, 1999). This scarless repair highlights the similarities between 
endometrial remodelling and development. The lack of scarring in the fetus is not related to fetal environment; neither amniotic fluid environment nor perfusion by fetal blood prevent scar formation in the wounded adult skin graft (Longaker et al., 1994). In the sheep fetus, the organization of collagen within the fetal wound is a key factor in the wound scarring pattern; the resultant collagen architecture is reticular and indistinguishable from that in normal tissue. Fetal skin also re-epithelializes faster than adult skin, and there is a reduced inflammatory response (in particular, fewer neutrophils), and a different growth factor response of the tissue. Recent investigations of cytokine profiles in fetal wounds indicate that diminished production of inflammatory cytokines such as IL-6 and IL-8 contribute to low inflammation (Liu et al., 2001). In IL-10 (antiinflammatory cytokine)-deficient fetuses, wounds heal with scarring, supporting a role for inflammation in the development of scars (Liechty et al., 2000). There could be important features in common with healing in the fetus, given that the endometrium heals without scarring.

Intestinal wound healing is also likely to share features with endometrial repair, given that both require repair of mucosal surfaces. Repair of mucosal injury anywhere throughout the gastrointestinal tract is a biphasic process. Initially, intestinal wounds are resurfaced very rapidly from epithelial cells at the edges of the defect. These appear to redifferentiate towards a migratory phenotype with specialized membrane cytoskeletal and matrix-receptor reorganizations and specialized matrix-dependent signalling patterns (Wilson and Gibson 1997; Basson, 2001). The migrating cells require a necrotic layer, consisting of dead cells, plasma exudates, mucus and fibrin, and if this is removed, restitution is impaired (Wallace et al., 1986). After re-epithelialization, maturation of the new epithelium occurs under the influence of numerous peptide and non-peptide regulators. The time course of this repair depends greatly on the severity and tissue depth of the injury (Wilson and Gibson, 1997).

Among the molecules important for wound healing in a range of situations are a wealth of growth factors and cytokines, extracellular matrix molecules such as fibronectin and hyaluronan and their cellular receptors (including the integrins and CD44), and matrix degrading enzymes such as MMPs. Not only the presence or absence of a factor but also the timing of its action appears to be important. For example, IL-1 and tumour necrosis factor $\alpha$ are both beneficial in the early stages of wound repair but deleterious in the later stages (Rumaiia and Borah, 2001). Although pharmacological application of growth factors and cytokines to wounds has not yielded dramatic clinical benefit, substantial experimental evidence from studies in mice has shown that blocking key molecules will prevent or seriously impair wound repair (Table 3). Many of these key molecules are also important in tissue degradation.

\section{Endometrial repair}

It has been proposed that repair of the human uterine surface is complete within $48 \mathrm{~h}$ after the first two menstrual days, and $60 \mathrm{~h}$ after mechanically induced trauma in the rodent (Ferenczy, 1976; Ludwig et al., 1990), on the basis of morphological data from both humans and experimental animals. Indeed, when only the epithelium is lost after oil injection in mice, restoration occurs within 45 min (Finn et al., 1989). Construction of the uterine epithelial surface appears to precede stromal expansion; stromal mitoses first appear only after re-epithelialization is complete (day 5 or 6 of the human menstrual cycle), coincident with rising oestrogen concentrations, and reach a peak on days 8-10 (Ferenczy et al., 1979). A similar sequence of events, with re-epithelialization preceding stromal mitosis, is seen in the rhesus monkey (Okulicz et al., 1997). Oestrogen and progesterone receptors (ER and $P R$ ) are detected in the glandular epithelium by day 3 , and by day 5 , when epithelial reconstruction is complete, strong positive staining for $E R$ and PR is present throughout the endometrium (Okulicz and Scarrell, 1998). Studies with tissue recombinations indicate that the uterine epithelium is required for stromal responsiveness to hormones, and may explain why reepithelialization is the first event in restoration (Bigsby, 2002). However, it is important to note that even in the absence of all hormonal support (after ovariectomy and endometriotomy), the endometrium stops bleeding and heals, indicating that normal wound healing mechanisms play a role in the reconstruction of the endometrium during menses and that this is facilitated by proliferative factors other than oestrogen.

Re-epithelialization. Scanning electron microscopy (Ferenczy, 1976; Ludwig et al., 1990) has revealed a dual origin for the restoration of the luminal epithelium. Regeneration begins in areas in which the mouths of basal glands are free from overlying degenerated tissue, and there is simultaneous and progressive epithelial outgrowth from these, and ingrowth from the intact peripheral surface membrane bordering the denuded basalis. The stromal tissue starts to grow only when the endometrial wound is completely re-epithelialized. This re-epithelialization has many features in common with that in wound healing in other tissues, but the molecular mechanisms are not yet known.

Vascular repair. Within 5 days of menstrual onset, the damaged endometrial vessels have been repaired (Ludwig and Spornitz, 1991). This repair occurs simultaneously with breakdown, as does re-epithelialization. Subsequent re-growth of vessels occurs under the influence of oestrogen, together with stromal expansion as the proliferative phase progresses.

Stem cells. Any tissue that undergoes self-renewal (for example, epidermis, haematopoietic system) must 
Table 3. Functional models resulting in impaired wound healing

\begin{tabular}{|c|c|c|c|}
\hline $\begin{array}{l}\text { Disrupted or inhibited } \\
\text { gene or protein }\end{array}$ & $\begin{array}{l}\text { Treatment, transgene or } \\
\text { knockout }(\mathrm{KO})\end{array}$ & Effect on wound healing & Reference \\
\hline \multicolumn{4}{|l|}{ ECM-related } \\
\hline MMP & Inhibitor & Inhibits moist skin re-epithelialization & Agren, 1999 \\
\hline Collagenase & Transgenic & $\begin{array}{l}\text { Retarded epithelial migration and } \\
\text { wound closure }\end{array}$ & Di Colandrea et al., 1998 \\
\hline MMP-3 (stromelysin-1) & $\mathrm{KO}$ & $\begin{array}{l}\text { Delayed wound repair, impaired scar } \\
\text { contraction, no effect on re-epithelialization }\end{array}$ & Builard et al., 1999 \\
\hline MMP-7 (matrilysin) & $\mathrm{KO}$ & $\begin{array}{l}\text { No epithelial migration, no change in size } \\
\text { of wound opening }\end{array}$ & Parks, 1999 \\
\hline $\mathrm{uPA}+\mathrm{MMP}$ & $\mathrm{KO}+$ inhibitor & No healing, no wound closure & Lund et al., 1999 \\
\hline uPA + fibrinogen & $\mathrm{KO} \times \mathrm{KO}$ & $\begin{array}{l}\text { Plasminogen } \mathrm{KO} \text { alone has delayed wound } \\
\text { healing, corrected by fibrinogen removal }\end{array}$ & Bugge et al., 1996 \\
\hline$\alpha \vee \beta 5$ integrin & $\mathrm{KO}$ & Normal & Huang et al., 2000 \\
\hline$\alpha 1 \beta 1$ integrin & $\mathrm{KO}$ & $\begin{array}{l}\text { ? MMPs, loss of feedback regulation of } \\
\text { collagen synthesis }\end{array}$ & Gardner et al., 1999 \\
\hline Vimentin & $\mathrm{KO}$ & $\begin{array}{l}\text { Delayed fibroblast migration into wound, } \\
\text { delayed healing }\end{array}$ & Eckes et al., 2000 \\
\hline \multicolumn{4}{|l|}{ Growth factor-related } \\
\hline Activin & Transgene & Increased epithelialization, increased scar tissue & Munz et al., 1999 \\
\hline Follistatin & Transgene & $\begin{array}{l}\text { Severely impaired wound healing, dermal } \\
\text { organization of collagen abnormal }\end{array}$ & Wankell et al., 2001 \\
\hline Smad3 & $\mathrm{KO}$ & $\begin{array}{l}\text { Accelerated wound healing, wound closure } \\
\text { and re-epithelialization enhanced }\end{array}$ & Ashcroft et al., 1999 \\
\hline BMP-6 & Transgene & $\begin{array}{l}\text { Delayed re-epithelialization and } \\
\text { scar formation }\end{array}$ & Kaiser et al., 1998 \\
\hline KGF receptor & $\mathrm{KO}$ & Delayed re-epithelialization & Werner et al., 1994 \\
\hline TGF $\beta 1$ & Oligo-deoxynucleotides & Reduced scarring & Choi et al., 1996 \\
\hline VEGF & Neutralizing antibody & $\begin{array}{l}\text { Inhibited wound angiogenesis and } \\
\text { granulation tissue formation }\end{array}$ & Howdieshell et al., 2001 \\
\hline IL-10 & $\mathrm{KO}$ & $\begin{array}{l}\text { Fetal wounds show increased inflammation } \\
\text { and heal with scars }\end{array}$ & Liechty et al., 2000 \\
\hline
\end{tabular}

ECM: extracellular matrix; MMP: matrix metalloproteinase; uPA: urokinase plasminogen activator; BMP: bone morphogenetic protein; KGF: keratinocyte growth factor; TGF $\beta 1$ : transforming growth factor $\beta 1$; VEGF: vascular endothelial cell growth factor; IL-10: interleukin 10.

establish a life-long population of relatively pliable stem cells. The classic perception that stem cells are undifferentiated is now not strictly held: stem cells can masquerade behind morphological and biochemical features normally attributed to undifferentiated cell types. Indeed, it has been suggested that the only infallible traits of stem cells are their robust proliferative capacity and their ability to self renew (Fuchs and Segre, 2000). It has been proposed that stem cell reservoirs will be present only in adult tissues that are capable of constant mature cell production or postinjury regeneration (Lemischka, 2001); the endometrium certainly fulfils these requirements. Identification of the microenvironments within the niches in a tissue where different types of precursor or stem cells reside is a major challenge for the future.

As early as 1944, Hartman showed that after experimental removal of all visible endometrium (endometriectomy), the entire primate endometrium could regenerate from the few endometrial cells remaining on the surface of the myometrium. Padykula (1991) subsequently postulated that there is a multipotent pool of stem cells within the deeper basalis layer in the human endometrium, capable of producing progenitor cells that further differentiate into epithelial, stromal and endothelial cells. However, there is no evidence to support a single progenitor cell for all types of endometrial cell and it is more likely that there are different precursor cells for each type of cell. In the endometrium in rabbits, quiescent cells in the bottom of the glands proliferate and migrate up through the glands to the lumen (Conti et al., 1984). Oestrogen administration results in recruitment of glandular quiescent cells into the cell cycle, but has no effect on luminal epithelial cells. After photodynamic epithelial destruction in the endometrium in rabbits, rapid re-epithelialization likewise occurs by proliferation originating in the deeper regions of the glands (Wyss et al., 1996). Thus, it appears that cells deep in the glands function as a population of stem cells. A similar mechanism is likely in the human endometrium; indeed, 
basal epithelial cells of some glands are located within the myometrium and may provide the precursors from which the endometrium can re-epithelialize, even after endometriectomy. Stem cells that act as precursors for endometrial stromal fibroblasts have not been identified, although in culture, an unusually high number of doublings has been reported for endometrial stromal cells (Holinka and Gurpide, 1987). Decidual stromal cells in culture express STRO-1, an antigen that identifies stromal precursors of the bone marrow (Garcia-Pacheco et al., 2001); whether this is present in non-decidualized stromal cells or in decidual cells in vivo is not known. As phenotypic alterations of cells in culture occur with time and can be affected by culture conditions, it may be that certain conditions favour the growth of subpopulations derived from a small number of stem cells within the initial tissue samples.

Proteolytic enzymes. During wound healing, cells are required to migrate rapidly into the wound site, via proteolytically generated pathways in the provisional matrix, to produce a new extracellular matrix (ECM) and to remodel the newly formed matrix. During menstruation, proteolytic enzymes including MMPs and serine proteases are present in abundance (Table 1) and it is difficult to establish whether their role is primarily in tissue breakdown or whether they also play a role in repair. Limited proteolysis is important for exposing cryptic cell-binding sites on the ECM that are needed for cell migration. Therefore, the proteinases that are localized to and activated at the contact areas of the ECM and the plasma membrane are likely to be the best candidate enzymes for regulating cell migration (Parks, 1999). These proteinases include MT-MMPs, MMP-2 and MMP-9, all of which are present in the endometrium during the menstrual phase of the human cycle (Salamonsen and Woolley, 1999). Other proteases may be important for the release and activation of growth factors needed for endometrial repair (for example, the release of fibroblast growth factor (FGF) from perlecan by the action of MMP-1 and -3 (Whitelock et al., 1996) and the activation of transforming growth factor $\beta$ (TGF $\beta$ ) and IL-1 $\beta$ from their precursors by the actions of MMP-2 and -9, respectively (Schonbeck et al., 1998; Yu and Stamenkovic, 2000)). MMP-7, which is strongly expressed in the endometrial epithelium during the menstrual phase, is important for re-epithelialization after wounding in the trachea (Parks et al., 2001); in MMP-7-null mice, such wounds do not re-epithelialize within $24 \mathrm{~h}$, the time taken in wildtype animals (Parks, 1999). Whether MMP-7 is equally important for reepithelialization of the human endometrium remains to be established.

Growth factors. A number of growth factors known to be important in wound healing are expressed in the endometrium and are likely to be important in endometrial repair. These growth factors can be derived from both stromal and epithelial cells or from leucocytes.

Activins. Activins (members of the TGF $\beta$ superfamily) are strongly upregulated during cutaneous wound healing (Munz et al., 1999), whereas mice overexpressing the natural inhibitor, follistatin, show a severe delay in wound healing (Wankell et al., 2001). However, the scar area is small when the wounds eventually heal in these mice, indicating a role for activin in scar formation too. Activins, their receptors and follistatin are all present in the human endometrium, with activin A localized particularly to the epithelium, decidualized stromal cells and leucocytes (Jones et al., 2002). During menstruation, activin A may be present in high concentrations in menstrual fluid and, if so, would be anticipated to play a role in repair mechanisms. Other members of the TGF $\beta$ superfamily including all three TGF $\beta$ s have also been implicated in wound healing (Table 3 ).

Keratinocyte growth factor (KGF). KGF is a member of the FGF family and its high affinity receptor is present on most types of epithelial cell. Over-expression of KGF in skin leads to hypertrophy of epidermis, although lack of KGF seems to be compensated for by FGF-10 (Werner, 1998). Skin wounds in receptor-deficient mice have severely delayed re-epithelialization, whereas addition of exogenous KGF to wounds stimulates reepithelialization. In rhesus monkeys, endometrial KGF is upregulated by progesterone and falls markedly during the luteal-to-follicular transition. KGF is not mitogenic on epithelial cells in the endometrium of this primate (Slayden et al., 2000), but stimulates spiral artery growth and inhibits glandular apoptosis during the secretory phase of the cycle. It may be that a different FGF family member contributes to epithelial regeneration in the endometrium. In humans, FGF-2 mRNA is present in the endometrial stromal compartment, whereas its receptor (FGF-R1) is present on both stromal and epithelial cells, indicating a potential role for FGF-2 in epithelial repair and stromal restoration (Sangha et al., 1997).

Hepatocyte growth factor (HGF). HGF is a mesenchymal-derived pleiotropic factor that mediates the interactions between mesenchymal and epithelial cells by acting as a mitogen on epithelial cells. It has been suggested that HGF is involved in the regeneration of several tissues. HGF promotes proliferation, migration and lumen formation of endometrial epithelial cells in vitro (Sugawara et al., 1997); whether these actions occur in vivo remains to be established.

Vascular endothelial cell growth factor (VEGF). Local administration of a neutralizing anti-VEGF antibody has implicated VEGF in wound angiogenesis (Howdieshell 


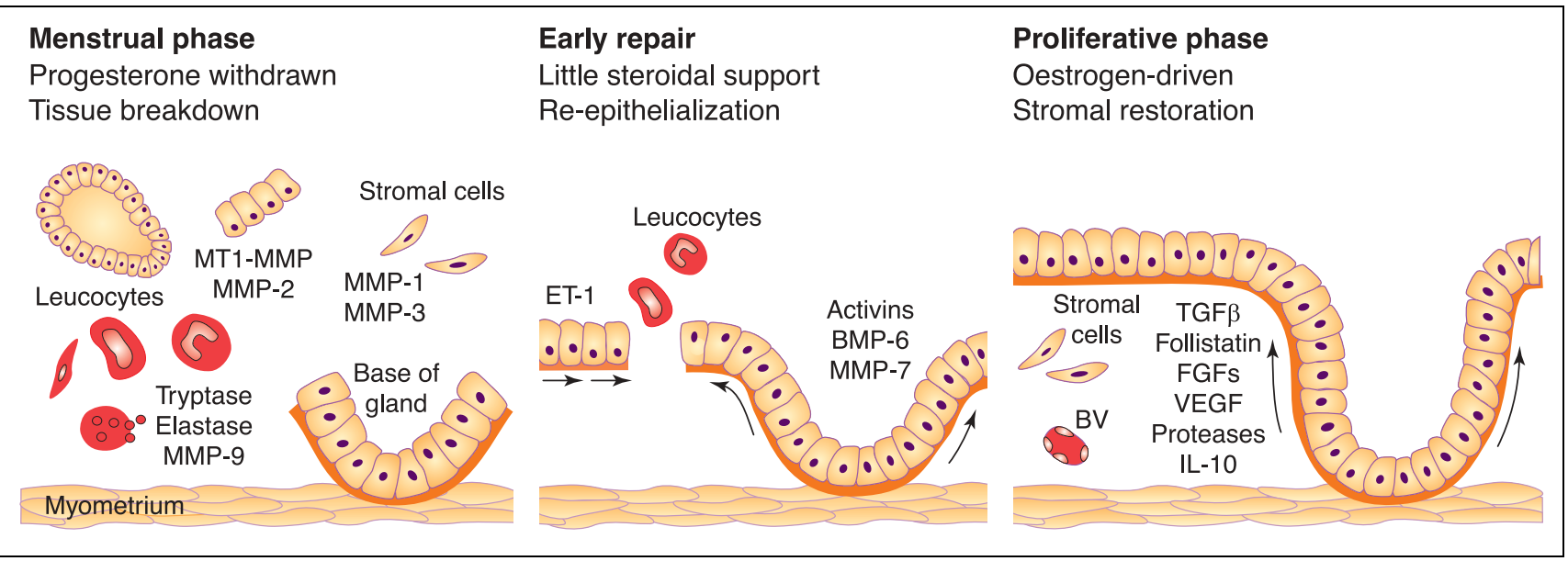

Fig. 2. Proposed scheme for tissue breakdown and restoration in the endometrium. During the menstrual phase, tissue is shed as a result of the action of matrix metalloproteinase (MMP) action, leaving basal parts of glands and patches of stroma. Re-epithelialization is very rapid, and occurs from the open mouths of the glands and from unshed portions of the luminal epithelium. Leucocyte products and a variety of other factors derived from the epithelium itself are postulated to play a role in re-epithelialization. Subsequent restoration of the underlying stroma includes proliferation of cells associated with blood vessels and endometrial stromal cells, along with the laying down of extracellular matrix. These events are postulated to occur under the influence of increasing oestrogen concentrations and are probably locally regulated by a number of growth factors and other regulatory factors. MMP: matrix metalloproteinases; ET-1: endothelin 1; BMP-6: bone morphogenetic protein 6; BV: blood vessel; TGF $\beta$ : transforming growth factor $\beta$; FGFs: fibroblast growth factors; VEGF: vascular endothelial cell growth factor; IL-10: interleukin 10.

et al., 2001). In both humans and rhesus macaques, VEGF expression peaks during post-menstrual repair, in conjunction with TGF $\alpha$, IL-1 $\beta$ or other growth factors (Graubert et al., 2001; Nayak and Brenner, 2002). Moreover, activation of its cognate receptor KDR occurs in the late menstrual and early proliferative phases. The other VEGF receptor, sFLT, is also increased during menstruation, although it peaks later than the receptors of KDR. This protein acts as a dominant negative receptor by sequestering VEGF from KDR, and may thus retard the wave of vascular repair (Graubert et al., 2001).

Endothelin. Endothelin, although known primarily as a vasoconstrictor, also has marked mitogenic actions. In the human endometrium, endothelin 1 is the predominant isoform and is maximally expressed during the late secretory and menstrual phases by epithelial, endothelial and decidualized stromal cells. It has been proposed that endothelin 1 has roles in both the cessation of bleeding and tissue repair (Salamonsen et al., 1999a).

Inflammatory cells. Inflammatory cells play an important role in cutaneous wound healing (Singer and Clark, 1999) and are present in substantial numbers in the menstruating endometrium (Salamonsen and Woolley, 1999). It is difficult to differentiate between the contribution of these cells to endometrial breakdown and their role in repair, but certainly during the early stage of repair, regulatory factors derived from leucocytes are likely to be important. For example, interactions among macrophages, eosinophils and their chemokines clearly contribute to epithelial growth in normal and cancer states including mammary gland development (GouonEvans et al., 2002).

Chemokines. Chemokines, cytokines best known for their chemoattractive properties, attract leucocytes into tissues and are present in many leucocytes and endometrial epithelial, stromal and vascular cells. Evidence now supports a broad range of functions for chemokines that indicate important roles in tissue repair (see Salamonsen et al., 2002). For example, IL-8, which is expressed in endometrial vessels (Jones et al., 1997), has angiogenic properties (Koch et al., 1992) and enhances re-epithelialization of skin grafts (Rennekampff et al., 2000). A proposed scheme for tissue restoration after breakdown in the endometrium is shown in Fig. 2.

\section{Uterine involution}

Uterine involution requires massive remodelling of the extracellular matrix in association with cell proliferation and apoptosis as the uterus returns to the pre-pregnancy state (Takamoto et al., 1998). This is related primarily to the loss of collagen. Postpartum involution of the uterus is markedly impaired in mice carrying mutations that make collagen type I resistant to collagenase action (Liu et al., 1995). Uterine involution has been studied most extensively in the rat; indeed the enzyme matrilysin (MMP-7) was first identified because of its high expression in the postpartum uterus where it reaches peak expression on days 1-2 (Woessner, 1996). Its regulation at this time is not fully understood, although 
loss of progesterone and mechanical distention are likely contributors. MMP-7 is localized to the epithelial cell surface in an MMP-7-HB-EGF-ErbB4 complex that is assembled by the membrane cell surface proteoglycan CD44. Postpartum uterine involution is accelerated in CD44 null mice (Yu et al., 2002). In these animals, MMP-7 is redistributed from the apical to the basal compartment, indicating that mislocalized MMP-7 activity results in accelerated basement membrane degradation. In MMP-7 and MMP-3 null mice, there are no changes in uterine involution; however, considerable upregulation of other MMPs occurs, presumably providing compensation (Rudolph-Owen et al., 1997). Neutrophil collagenase (MMP-8) is also highly expressed in the postpartum uterus, and can be activated by MMP-7 (Balbin et al., 1998).

The puerperium in women is defined as the period of 6-8 weeks after delivery during which the uterus, which weighs more than one kilogram soon after delivery, undergoes physiological involution and returns to the non-pregnant state. A recent longitudinal study using ultrasonography has provided important information (Mulic-Lutvica et al., 2001), supporting earlier histological data (Williams, 1931). During the first three days postpartum, the endometrium is very thin; a variable amount of decidual tissue can be retained after labour. A normal healing process appears to occur from day 7 to day 17 , along with abundant shedding of lochia. From days 26-56, the endometrium appears to be inactive (probably resembling proliferative phase tissue), and reflects the completed involution. However, because of the difficulties of sampling, nothing is known specifically of the molecular mechanisms underlying uterine involution in women.

\section{Conclusion}

Although the past decade has seen considerable advance in our understanding of the processes of tissue damage and breakdown in the endometrium, almost nothing is known of how endometrial repair is achieved after menstruation or parturition. It is clear that repair is very rapid, that it occurs without scarring, and that the endometrium can be regenerated even after its almost complete removal. Many of the factors involved in tissue remodelling in the uterus are otherwise most commonly expressed during development or in pathologies or cancer. Although mechanisms of breakdown are considered critical in providing explanations for abnormal uterine bleeding in women, repair mechanisms are likely to be of equal importance and it is hoped that a clearer understanding of these mechanisms will be achieved during the current decade.

The author thanks many members of the Uterine Biology Laboratory at Prince Henry's Institute who have contributed to studies cited in this review and particularly $R$. Jones and
M. Brasted for critical reading of the manuscript. The assistance of S. Panckridge with Figs 1 and 2 and of S. Park in preparation of the manuscript is gratefully acknowledged. The author is supported by a Principal Research Fellowship from the NHMRC (number 143798), and work cited from her laboratory is supported by an NHMRC project grant (number 169003).

\section{References}

Key references are identified by asterisks.

Agren MS (1999) Matrix metalloproteinases (MMPS) are required for re-epithelialization of cutaneous wounds Archives of Dermatological Research 291 583-590

Ashcroft GS, Yang X, Glick AB et al. (1999) Mice lacking Smad3 show accelerated wound healing and an impaired local inflammatory response Nature Cell Biology 1260-266

Balbin M, Fueyo A, Knauper V, Pendas AM, Lopez JM, Jimenez MG, Murphy G and Lopez-Otin C (1998) Collagenase 2 (MMP-8) expression in murine tissue-remodeling processes. Analysis of its potential role in postpartum involution of the uterus The Journal of Biological Chemistry 27323 959-23968

Basson MD (2001) In vitro evidence for matrix regulation of intestinal epithelial biology during mucosal healing Life Science 693005-3018

Bigsby RM (2002) Control of growth and differentiation of the endometrium: the role of tissue interactions Annals of the New York Academy of Sciences $955110-117$

Brandon JM (1990) Decidualization in the post-partum uterus of the mouse Journal of Reproduction and Fertility 88 151-158

Bugge TH, Kombrinck KW, Flick MJ, Daugherty CC, Danton MJ and Degen JL (1996) Loss of fibrinogen rescues mice from the pleiotropic effects of plasminogen deficiency Cell 87 709-719

Builard KM, Lund L, Mudgett JS, Mellin TN, Hunt TK, Murphy B, Ronan J, Werb Z and Banda MJ (1999) Impaired wound contraction in stromelysin-I-deficient mice Annals of Surgery 230260-265

Choi BM, Kwak HJ, Jun CD, Park SD, Kim KY, Kim HR and Chung HT (1996) Control of scarring in adult wounds using antisense transforming growth factor-beta 1 oligodeoxynucleotides Immunology and Cell Biology 74 144-150

Conti CJ, Gimenez-Conti IB, Conner EA, Lehman JM and Gerschenson LE (1984) Estrogen and progesterone regulation of proliferation, migration, and loss in different target cells of rabbit uterine epithelium Endocrinology 114 345-351

Curry TE and Osteen KG (2001) Cyclic changes in the matrix metalloproteinase system in the ovary and uterus Biology of Reproduction 64 1285-1296

Deyer TW, Ashton-Miller JA, Van Baren PM and Peariman MD (2000) Myometrial contractile strain at uteroplacental separation during parturition American Journal of Obstetrics and Gynecology 183 156159

Di Colandrea T, Wang L, Wille J, D'Armiento J and Chada KK (1998) Epidermal expression of collagenase delays wound-healing in transgenic mice Journal of Investigative Dermatology 111 1029-1033

Eckes B, Colucci-Guyon E, Smola H, Nodder S, Babinet C, Krieg T and Martin P (2000) Impaired wound healing in embryonic and adult mice lacking vimentin Journal of Cell Science 1132455-2462

Ferenczy A (1976) Studies on the cytodynamics of human endometrial regeneration. II. Transmission electron microscopy and histochemistry American Journal of Obstetrics and Gynecology 124 582-595

Ferenczy A, Bertrand G and Gelfand MM (1979) Studies on the cytodynamics of human endometrial regeneration. III. In vitro short-term incubation historadioautography American Journal of Obstetrics and Gynecology 134 297-304

Finn CA (1986) Implantation, menstruation and inflammation Biological Reviews of the Cambridge Philosophical Society 61 313-328

Finn CA, Pope MD and Milligan SR (1989) A study of the early morphological changes initiated in the uterine luminal epithelium by substances (oil and carrageenan) which induce the decidual cell reaction in mice Journal of Reproduction and Fertility 86 619-626 
*Fuchs E and Segre JA (2000) Stem cells: a new lease on life Cell $100143-$ 155

Garcia-Pacheco JM, Oliver C, Kimatral M, Blanco FJ and Olivares EG (2001) Human decidual stromal cells express CD34 and STRO-1 and are related to bone marrow stromal precursors Molecular Human Reproduction 71151-1157

Gardner H, Broberg A, Pozzi A, Laato M and Heino J (1999) Absence of integrin alpha1 beta1 in the mouse causes loss of feedback regulation of collagen synthesis in normal and wounded dermis Journal of Cell Science $112263-272$

Gouon-Evans V, Lin EY and Pollard JW (2002) Requirement of macrophages and eosinophils and their cytokines/chemokines for mammary gland development Breast Cancer Research 4 155-164

Graubert MD, Ortega MA, Kessel B, Mortola JF and Iruela-Arispe ML (2001) Vascular repair after menstruation involves regulation of vascular endothelial growth factor-receptor phosphorylation by sFLT-1 American Journal of Pathology 1581399-1410

Hartman CG (1944) Regeneration of the monkey uterus after surgical removal of the endometrium and accidental endometriosis Western Journal of Surgical Obstetrics and Gynecology 52 87-102

Hisaw FL and Hisaw FLJ (1961) Action of estrogen and progesterone on the reproductive tract of lower primates. In Sex and Internal Secretions (Vol. 1) pp 556-568 Ed. WC Young. Williams and Wilkins, Baltimore

Holinka CF and Gurpide E (1987) Proliferative potential and polymorphism of human endometrial stromal cells Gynecological Endocrinology $\mathbf{1}$ $71-81$

Howdieshell TR, Callaway D, Webb WL, Gaines MD, Procter CD, Jr, Sathyanarayana, Pollock JS, Brock TL and McNeil PL (2001) Antibody neutralization of vascular endothelial growth factor inhibits wound granulation tissue formation Journal of Surgical Research 96 $173-182$

Huang X, Griffiths M, Wu J, Farese RV, Jr and Sheppard D (2000) Normal development, wound healing, and adenovirus susceptibility in beta5deficient mice Molecular and Cellular Biology 20 755-759

Hulboy DL, Rudolph LA and Matrislan LM (1997) Matrix metalloproteinases as mediators of reproductive function Molecular Human Reproduction 3 $27-46$

Jones RL, Kelly RW and Critchley HO (1997) Chemokine and cyclooxygenase-2 expression in human endometrium coincides with leukocyte accumulation Human Reproduction 12 1300-1306

Jones RL, Salamonsen LA and Findlay JK (2002) Potential roles for endometrial inhibins, activins and follistatin during human embryo implantation and early pregnancy Trends in Endocrinology and Metabolism 13 144-150

Kaiser S, Schirmacher P, Philipp A, Protschka M, Moll I, Nicol K and Blessing $\mathbf{M}$ (1998) Induction of bone morphogenetic protein-6 in skin wounds. Delayed re-epitheliazation and scar formation in BMP-6 overexpressing transgenic mice Journal of Investigative Dermatology $1111145-1152$

Kelly RW, Illingworth P, Baidie G, Leask R, Brouwer S and Calder AA (1994) Progesterone control of interleukin-8 production in endometrium and chorio-decidual cells underlines the role of the neutrophil in menstruation and parturition Human Reproduction 9253-258

King A, Burrows T, Verma S, Hiby S and Loke YW (1998) Human uterine lymphocytes Human Reproduction Update 4 480-485

Koch AE, Polverini PJ, Kunkel SL, Harlow LA, DiPietro LA, Einer VM, Einer SG and Strieter RM (1992) Interleukin-8 as a macrophage-derived mediator of angiogenesis Science 258 1798-1801

Lemischka I (2001) Stem cell dogmas in the genomics era Reviews of Clinical and Experimental Hematology 5 15-25

Liechty KW, Kim HB, Adzick NS and Crombleholme TM (2000) Fetal wound repair results in scar formation in interleukin-10-deficient mice in a syngeneic murine model of scarless fetal wound repair Journal of Pediatric Surgery 35 866-872

Liu X, Wu H, Byrne M, Jeffrey J, Krane S and Jaenisch R (1995) A targeted mutation at the known collagenase cleavage site in mouse type 1 collagen impairs tissue remodeling The Journal of Cell Biology 130 227-237

Liu W, Cao Y and Longaker MT (2001) Gene therapy of scarring: a lesson learned from fetal scarless wound healing Yonsei Medical Journal 42 634-645

Lockwood CJ and Schatz F (1996) A biological model for the regulation of peri-implantational hemostasis and menstruation Journal of the Society for Gynecological Investigation 3159-165

Longaker MT, Whitby DJ, Ferguson MW, Lorenz HP, Harrison MR and Adzick NS (1994) Adult skin wounds in the fetal environment heal with scar formation Annals of Surgery 219 65-72

Ludwig H and Spornitz UM (1991) Microarchitecture of the endometrium by scanning electron microscopy: menstrual desquamation and remodelling Annals of the New York Academy of Sciences 622 28-46

Ludwig H, Metzger H and Fraull M (1990) Endometrium: tissue remodelling and regeneration. In Contraception and Mechanisms of Endometrial Bleeding pp 441-466 Eds C d'Arcangues, IS Fraser, JR Newton and $\checkmark$ Odlind. Cambridge University Press, Cambridge

Lund LR, Romer J, Bugge TH, Nielsen BS, Frandsen TL, Degen JL, Stephens RW and Dano K (1999) Functional overlap between two classes of matrix-degrading proteases in wound healing EMBO Journal 184645 4656

Marbaix E, Kokorine I, Moulin P, Donnez J, Eeckhout $\mathrm{Y}$ and Courtoy PJ (1996) Menstrual breakdown of human endometrium can be mimicked in vitro and is selectively and reversibly blocked by inhibitors of matrix metalloproteinases Proceedings National Academy of Sciences USA 93 $9120-9125$

Markee JE (1940) Menstruation in intraocular endometrial transplants in the rhesus monkey Contributions to Embryology 177 220-230

Mulic-Lutvica A, Bekuretsion M, Bakos O and Axeisson O (2001) Ultrasonic evaluation of the uterus and uterine cavity after normal, vaginal delivery Ultrasound Obstetrics and Gynecology 18491-498

Munz B, Smola H, Engelhardt F, Bleuel K, Brauchle M, Lein I, Evans LW, Huyiebroeck D, Balling R and Werner S (1999) Overexpression of activin $\mathrm{A}$ in the skin of transgenic mice reveals new activities of activin in epidermal morphogenesis, dermal fibrosis and wound repair $E M B O$ Journal 185205-5215

Nayak NR and Brenner RM (2002) Vascular proliferation and vascular endothelial growth factor expression in the rhesus macaque endometrium Journal of Clinical Endocrinology and Metabolism $\mathbf{8 7}$ 1845-1855

Okulicz WC and Scarrell R (1998) Estrogen receptor alpha and progesterone receptor in the rhesus endometrium during the late secretory phase and menses Proceedings of the Society for Experimental Biology and Medicine 218316-321

Okulicz WC, Ace Cl and Scarrell R (1997) Zonal changes in proliferation in the rhesus endometrium during the late secretory phase and menses Proceedings of the Society for Experimental Biology and Medicine 214 132-138

Padykula HA (1991) Regeneration in the primate uterus: the role of stem cells Annals of the New York Academy of Sciences 622 47-56

* Parks WC (1999) Matrix metalloproteinases in repair Wound Repair and Regeneration 7 423-432

Parks WC, Lopez-Boado YS and Wilson CL (2001) Matrilysin in epithelial repair and defense Chest $\mathbf{1 2 0} 36 \mathrm{~S}-41 \mathrm{~S}$

Rennekampff HO, Hansbrough JF, Kiessig V, Dore C, Sticherling M and Schroder JM (2000) Bioactive interleukin-8 is expressed in wounds and enhances wound healing Journal of Surgical Research 93 41-54

Riley SC, Leask R, Denison FC, Wisely K, Calder AA and Howe DC (1999) Secretion of tissue inhibitors of matrix metalloproteinases by human fetal membranes, decidua and placenta at parturition Journal of Endocrinology 162 351-359

Roberts DK, Parmley TH, Walker NJ and Horbeit DV (1992) Ultrastructure of the microvasculature in the human endometrium throughout the normal menstrual cycle American Journal of Obstetrics and Gynecology 1661393-1406

Rudolph-Owen LA, Hulboy DL, Wilson CL, Mudgett J and Matrisian LM (1997) Coordinate expression of matrix metalloproteinase family members in the uterus of normal, matrilysin-deficient, and stromelysin1-deficient mice Endocrinology 138 4902-4911

Rumalia VK and Borah GL (2001) Cytokines, growth factors, and plastic surgery Plastic and Reconstructive Surgery 108719-733 
Salamonsen LA and Lathbury LJ (2000) Endometrial leukocytes and menstruation Human Reproduction Update 6 16-27

Salamonsen LA and Woolley DE (1999) Menstruation: induction by matrix metalloproteinases and inflammatory cells Journal of Reproductive Immunology $4 \mathbf{4}$ 1-27

Salamonsen LA, Marsh MM and Findlay JK (1999a) Endometrial endothelin: regulator of uterine bleeding and endometrial repair Clinical and Experimental Pharmacology and Physiology 26154-157

Salamonsen LA, Kovacs G and Findlay JK (1999b) Current concepts of the mechanisms of menstruation. In Baillière's Clinical Obstetrics and Gynaecology, Dysfunctional Uterine Bleeding pp 161-179 Ed. SK Smith. Baillière Tyndall, London

*Salamonsen LA, Zhang J and Brasted M (2002) Leukocyte networks and human endometrial remodelling Journal of Reproductive Immunology 57 95-108

Samuels P and Tan AK (1999) Fetal scarless wound healing Journal of Otolaryngology 28 296-302

Sangha RK, Li XF, Shams M and Ahmed A (1997) Fibroblast growth factor receptor-1 is a critical component for endometrial remodeling: localization and expression of basic fibroblast growth factor and FGFR1 in human endometrium during the menstrual cycle and decreased FGF-R1 expression in menorrhagia Laboratory Investigation 77 389402

Schonbeck U, Mach F and Libby $\mathbf{P}$ (1998) Generation of biologically active IL-1 beta by matrix metalloproteinases: a novel caspase-1-independent pathway of IL-1 beta processing Journal of Immunology 161 3340-3346

*Singer AJ and Clark RA (1999) Cutaneous wound healing New England Journal of Medicine 341 738-746

Slayden OD, Rubin JS, Lacey DL and Brenner RM (2000) Effects of keratinocyte growth factor in the endometrium of rhesus macaques during the luteal-follicular transition Journal of Clinical Endocrinology and Metabolism 85 275-285

Sugawara J, Fukaya T, Murakami T, Yoshida H and Yajima A (1997) Hepatocyte growth factor stimulated proliferation, migration, and lumen formation of human endometrial epithelial cells in vitro. Biology of Reproduction 57 936-942

Takamoto N, Leppert PC and Yu SY (1998) Cell death and proliferation and its relation to collagen degradation in uterine involution of rat Connective Tissue Research 37 163-175

Tsatas D, Baker MS and Rice GE (1999) Differential expression of proteases in human gestational tissues before, during and after spontaneous-onset labour at term Journal of Reproduction and Fertility 116 43-49

Wallace JL and Whittle BJ (1986) The role of extracellular mucus as a protective cap over gastric mucosal damage Scandinavian Journal of Gastroenterology 125 Supplement 1 79-85

Wankell M, Munz B, Hubner G, Hans W, Wolf E, Goppelt A and Werner S (2001) Impaired wound healing in transgenic mice overexpressing the activin antagonist follistatin in the epidermis EMBO Journal $205361-$ 5372
Werner S (1998) Keratinocyte growth factor: a unique player in epithelia repair processes Cytokine Growth Factor Reviews 9 153-165

Werner S, Smola H, Liao X, Longaker MT, Krieg T, Hofschneider PH and Williams LT (1994) The function of KGF in morphogenesis of epithelium and re-epithelialization of wounds Science 266 819-822

Whitelock JM, Murdoch AD, lozzo RV and Underwood PA (1996) The degradation of human endothelial cell-derived perlecan and release of bound basic fibroblast growth factor by stromelysin, collagenase, plasmin, and heparanases The Journal of Biological Chemistry 271 10079-10086

Williams JW (1931) Regeneration of the uterine mucosa after delivery with special reference to the placental site American Journal of Obstetrics and Gynecology 22 664-696

Wilson AK and Gibson PR (1997) Epithelial migration in the colon: filling in the gaps Clinical Science 93 97-108

Woessner JF, Jr (1996) Regulation of matrilysin in the rat uterus Biochemistry and Cell Biology 74 777-784

Wyss P, Steiner R, Llaw LH, Wyss MT, Ghazarians A, Berns MW, Tromberg BJ and Tadir Y (1996) Regeneration processes in rabbit endometrium: a photodynamic therapy model Human Reproduction 11 19921997

Xu P, Alfaidy N and Challis JR (2002) Expression of matrix metalloproteinase (MMP)-2 and MMP-9 in human placenta and fetal membranes in relation to preterm and term labor Journal of Clinical Endocrinology and Metabolism 87 1353-1361

Yu Q and Stamenkovic I (2000) Cell surface-localized matrix metalloproteinase-9 proteolytically activates TGF-beta and promotes tumor invasion and angiogenesis Genes and Development 14 163-176

Yu WH, Woessner JF, Jr, McNeish JD and Stamenkovic I (2002) CD44 anchors the assembly of matrilysin/MMP-7 with heparin-binding epidermal growth factor precursor and ErbB4 and regulates female reproductive organ remodeling Genes and Development $16307-$ 323

Zhang J and Salamonsen LA (1997) Tissue inhibitor of metalloproteinases (TIMP)-1, -2 and -3 in human endometrium during the menstrual cycle Molecular Human Reproduction 3 735-741

Zhang J and Salamonsen LA (2002a) Expression of hypoxia-inducible factors in human endometrium and suppression of matrix metalloproteinases under hypoxic conditions do not support a major role for hypoxia in regulating tissue breakdown at menstruation Human Reproduction $17265-274$

${ }^{*}$ Zhang J and Salamonsen LA (2002b) In vivo evidence for active matrix metalloproteinases in human endometrium supports their role in tissue breakdown at menstruation Journal of Clinical Endocrinology and Metabolism $872346-2351$

Zhang J, Hampton AL, Nie G-Y and Salamonsen LA (2000) Progesterone inhibits activation of latent matrix metalloproteinase (MMP)-2 by membrane-type 1 MMP: enzymes coordinately expressed in human endometrium Biology of Reproduction 62 85-94 